Cuestiones de filosofía

ISSN: 0123-5095

Vol. 1 - No. 17

Año 2015

pp. $55-64$

\title{
¿ES POSIBLE DESLIGAR LA EDUCACIÓN DEL MERCADO? POLITIZAR LA EDUCACIÓN
}

\section{Is it possible to untie education from the market? To politicize education}

\author{
Héctor Mauricio Cataldo-González* \\ titoon1@gmail.com \\ Universidad de Artes y Ciencias Sociales (Chile)
}

Fecha de recepción: 23/11/2014

Fecha de evaluación: 14/02/2015

Fecha de aprobación: 7/09/2015

\section{Resumen}

Desarrolla argumentos para sostener la separación entre la educación y el mercado, y despliega la idea de una politización de la educación contemporánea como manera de impulsar el re-nacimiento de un espacio público cuyo contenido no sean las relaciones de mercado, sino forjar un mundo común. La crítica a la mercantilización de la educación estriba en la generación y consolidación de ciudadanos irresponsables, es decir, preocupados única y exclusivamente de satisfacer sus necesidades, usando a los otros ciudadanos como medio para ello.

Palabras clave: Educación, Política, Individualismo, Mercado.

* Doctor en Filosofía, Escuela Latinoamericana de Postgrado, ELAP, Universidad ARCIS, Santiago de Chile. 


\begin{abstract}
This paper develops the arguments, that sustains the separation between the education from the market, and displays the contemporary education politization's idea, as a way to impulse the public space revival, where its contents should not be the market relationships, but those to forge a common world. The critique to the education merchandizing lies on the generation and consolidation of some irresponsible citizens, that are preoccupied only and exclusively to satisfy their own necessities, by using the other citizens as a mean to achieve it.
\end{abstract}

Keywords: Education, Politics, Individualism, Market.

Es vasta la literatura para mostrar que el nacimiento de la escuela pública está ligado al también naciente mercado moderno y a su desarrollo (Bowen, 1992). Los principios con los cuales la modernidad comienza su despliegue en Occidente (América Latina incluida) expresan con claridad la tríada libertad-igualdad-propiedad: por medio del trabajo, los ciudadanos libres pueden obtener el máximo de beneficio, ocupando las habilidades y capacidades que naturalmente yacen en cada uno de nosotros/as. Este beneficio es legítimo y legal, siempre y cuando lo logre sin ser un impedimento u obstáculo para la satisfacción de los intereses de los otros. Bien sabemos, hasta el día de hoy, que lograr satisfacer nuestros intereses a partir de estas premisas es la expresión de una utopía. La generación, administración y mantención de riqueza está preñada de trampas, subterfugios, engaños, muertes, sobornos, coacciones, irresponsabilidades y violencia. El derecho moderno guarda en su seno esta contradicción (Esposito, 2005).

Entonces, ¿es posible desligar la educación del mercado? Seguramente se dirá que tal pretensión es vacía, puesto que la educación moderna, y la pública-estatal en particular, nace de la mano del mercado, y desligarla de él sería un contrasentido. Tal argumentación parte de una irrestricta naturaleza de la educación, como si educar hubiese sido siempre igual. Cabe recordar que en las polis griegas, de Esparta yAtenas, por ejemplo, la educación estaba encaminada a una formación distinta de la económica (Jaeger, 1957); en ambas, no se educaba para la economía ${ }^{1}$. En este

1 Particularmente en Atenas, y en menor medida en Esparta, podríamos llamar "pública" a esa educación en cuanto el concepto de público apela al ámbito de la política, esto es, que en Atenas una educación pública es una educación política. 
sentido, el pensamiento liberal moderno "descubre"2 que tenemos una serie de cualidades que nos perfilan como homo economicus ${ }^{3}$. Dejando de lado, por el momento, que existan estas cualidades naturales en cada uno de nosotros, diremos que lo que se inaugura modernamente, y que la escuela pública moderna occidental es la expresión de aquello, es una nueva concepción antropológica de los seres humanos, a saber, el que somos seres económicos ante todo. La escuela moderna puede desplegar aquella concepción, como argumentará Pablo Pineau et al., 2001.

Estas cualidades, a su vez, expresan el conflicto por un nиеvo mundo. Este nuevo mundo es el del individuo libre, igual jurídicamente a los otros, pero desigual socialmente; propietario, a lo menos de su cuerpo, que por medio de la autonomía de la voluntad, de la razón y el trabajo puede otorgarse la satisfacción de sus intereses. Estas cualidades, que están en la base de la educación institucional de los nacientes y futuros Estados-nacionales, expresan un conflicto que ocurre materialmente, es decir, un conflicto que está determinado por el modo como las personas se las arreglan para mantenerse vivas. En este sentido, la educación es la manera como se reproducen prácticas, procedimientos, herramientas, todas ellas destinadas a conservar el modo de vida que "nos hemos dado". Esta manera de vivir no se le comunica a los nuevos o recién llegados a la sociedad para que decidan si quieren o no vivir de este modo. A los que nacen no se les pregunta si aceptan el modo de vivir al que llegan; se impone. El modo de vida que se impone es aquel que parte de la comprensión de que las personas, y las familiasson pequeñas "unidades económicas"4. Lo que se reproduce, entonces, son las condiciones para la realización de relaciones "personales" de mercado, esto es, relaciones humanas mediadas por los contenidos de la disciplina económica moderna y contemporánea. Por supuesto que esta reproducción es hegemónica, y la educación institucional busca, precisamente, disputar el territorio de dominación con las otras"formaciones educativas".

\footnotetext{
Inventar, debiéramos decir.

"Hombre económico" como lo definiría la escuela de economía clásica.

4 Si naturalmente tenemos capacidades para crear los medios para satisfacer nuestros intereses particulares y, a su vez, la familia es el pilar de la sociedad, entonces habrá que conceder que la familia es, en principio, una unidad económica, esto es, una organización mínima jerárquica que genera medios de vida, administra riqueza y se preocupa por la existencia biológica de sus miembros. Cada familia, por tanto, debe procurar aquellas satisfacciones. De no poder satisfacerlas, la responsabilidad no es del Estado ni de los otros, sino de los propios miembros jerarquizados que no han sabido proceder con sus habilidades y capacidades naturales.
} 
De este modo, pongo en evidencia lo siguiente: transformar la educación sin transformar las condiciones de posibilidad de su implementación equivale a mejorarla, adaptarla, sofisticarla, pero para el mercado (Althusser, 1988; Foucault, 2002 y 2008; Mészàros, 2008). El perjuicio de implementar los principios del mercado como principios reguladores de las relaciones societales estriba en que se considera a los otroscomo un medio para un fin (Horkheimer, 1973). Al lucrar no se puede exigir que la dignidad esté primero, puesto que en la propia naturaleza del lucro importa la ganancia que se obtiene por medio de la energía y la fuerza del cuerpo, de la inteligencia y del cansancio de los otros. El trato con el otro está regulado desde el beneficio económico que se logre. Así, cuando se habla de una educación para el mercado, se habla de un tipo de formación educativa que no solo disciplina para el trabajo y el trato laboral con los otros, sino que, además, enseña a tratar a los otros como si fuesen fuentes de ganancia, de energía. Con las reformas educativas lo que se hace es darles mayor sofisticación, eficacia y eficiencia a estos tratos y relaciones.

Entonces, ¿tiene sentido plantear la separación de la educación y el mercado? La separación apela a desprivilegiar la preeminencia de los criterios de mercado en el ejercicio educativo. Tal rotura, considero, puede derivar en cualquier otra ligazón, como, por ejemplo, la de ligar la escuela con la religión o con la raza. Como mencioné, desligar la educación del mercado no es un capricho o un juego antojadizo. Mientras la educación esté ligada al mercado, la formación será pensada en función de la dinámica misma del mercado, a saber, la de cuerpos dispuestos a gastarse como energía no renovable para el beneficio de otros.

En esta línea de argumentación se sigue que el liberalismo requiere de la despolitización de los ciudadanos, esto es, de que estos solo se preocupen de sí mismos, bajo la premisa de que al preocuparse de sí mismos no hay necesidad de preocuparse de todos (Hayek, 1975; Mises, 1996). Esta ocupación de sí no solo crea ciudadanos especializados en el ejercicio político (políticos profesionales, ciudadanos que hacen de la política un trabajo, lo que genera una contradicción en el propio ejercicio político), sino que también hace posible la separación, ilusoria por lo demás ${ }^{5}$, de los otros. Esta separación provoca la imposibilidad de generar mundo. Este concepto requiere de la máxima preocupación: no se trata únicamente del mundo-de-la-vida (Lebenswelt), del mundo circundante. La relevancia de tal concepto estriba en su latir político. Refiere a lo que los ciudadanos forjan en común, y esto que forjan no es precisamente a partir de una relación con la naturaleza, al modo de intervenirla modificándola en

5 El método fenomenológico da cuenta de esta "realidad". 
beneficio común o personal (entendiendo ambos conceptos en relación con la propiedad, es decir, lo común sería aquí lo que beneficia a cada uno); más bien, se trata de lo que surge entre ciudadanos, y este entre no es un espacio físico, natural, dado. El entre es el cum, el con, el de-con (Arendt, 1998;Luc-Nancy; Esposito, 2003). El mundo es, entonces, aquello que hay en común entre ciudadanos. El contenido del mundo no es solo lo que podemos percibir, sino "aquello que podemos decir" acerca de él. Opinar se torna de suma relevancia; por ello la responsabilidad es relevante, puesto que se requiere de ciudadanos que puedan res-ponder por sus actos. Esta opinión es la doxa a la que Platón despreciaba con toda su "alma". Opinar es relevante porque se entrega a los otros aquello que les pertenece y que los otros, por su propia condición, no pueden acceder a ella, puesto que no son aquel cuerpo que percibe y puede decir tal o cual opinión. Pero no estamos hablando de percibir la naturaleza o las cosas, únicamente. Más bien nos referimos a percibir "los asuntos que nos involucran a todos", no únicamente a mí, como por ejemplo, las leyes y la institucionalidad que nos rigen. Se trataría, en este sentido, de una opinión acerca de las leyes y la institucionalidad vigente. Pero esta opinión no puede ser reducida a catarsis, es decir, no se trata de simplemente hablar; no se trata de la opinión televisiva, radial o en internet (Brossat, 2008). Se trata de una opinión que sea tomada en serio, lo que significa que estas opiniones sean pensadas. ¿Qué quiere decir que una opinión sea pensada? El pensar, y en esto sigo a Hannah Arendt, ocurre "dentro" de mí. Que ocurra "dentro de mî” quiere decir que para pensar debo suspender el "fuera de mî', esto es, debo prescindir de los datos de la percepción, aunque, claro esté, no dejo por ello de seguir percibiendo. Este "dentro de mî" es lo que Arendt especificó con la palabra solitud, a saber, el diálogo silencioso de uno consigo mismo, diálogo que se rompe cuando nos vemos afectados por el “fuera de mî'. Este diálogo en mí supone a dos, por tanto, la interrupción lo que hace es provocar el uno. Provoca la unidad de mí. Pero, al mismo tiempo que la interrupción ocurre, se acaba el pensar. Pensar, entonces, es un diálogo que ocurre en el interior de cada uno; es el uno hablándose. Ahora bien, ¿puede impedirse tal diálogo? Por un lado, la ausencia de lenguaje puede impedirlo. En efecto, ¿cómo hablar conmigo mismo si no tengo el "instrumento" para hacerlo, es decir, la lengua, el idioma? Por otro lado, si el pensar es interrumpido por la exterioridad, por los estímulos o por la propia actividad del cuerpo (la satisfacción de las necesidades vitales o no de existencia), ¿cómo pensar si estas interrupciones son constantes, latentes, permanentes, es decir, si se encuentran en una situación donde no es posible desenfocarse de lo externo?

Indudablemente, pensar es inmanente a educar. Para pensar requiero de la lengua, pero la lengua no es un instrumento que, por definición, me pertenezca; no es mío. 
Lo que sí ocurre es que la lengua la puedo usar. La lengua es prestada; encargada a mí por el común de los hablantes de esa lengua. Indudablemente, la escuela juega aquí un papel fundamental. Sin embargo, es la segunda manera de impedir el pensar la que más me interesa. En general, no todo lo que se piensa corresponde a lo que de hecho ocurre; pero sí se puede pensar con respecto a lo que ocurre, por ejemplo, en el ejercicio ético o moral. Son variados los ejemplos de dilemas éticos: el médico que "miente" acerca de la enfermedad de su paciente, a petición de la esposa de este, para que no sufra otro paro cardíaco y así poder tenerlo vivo más tiempo; aquíel médico tomó una decisión que pensó es la correcta. Habráquienes considerarán que la verdad debe anteponerse a todo, incluso en estas situaciones que pueden causar la muerte. Lo esencial aquí es que el pensar es el resultado de una exigencia exterior, que bajo ninguna circunstancia puede tomarse como lo real. El médico del ejemplo podrá argumentar porqué tomó esa decisión, y solo lo podrá hacer, esto es, responsabilizarse de sus actos, porque lo pensó. Pues bien, ¿qué ocurre cuando las condiciones reales impiden pensar lo que haré o diré? Ocurre que nos enfrentamos, entonces, a ciudadanos irresponsables, es decir, imposibilitados de fundamentar los motivos de sus actos o, lo que sería más terrible aún, estando en desacuerdo con los actos que deben realizar, los realizan de todos modos (Arendt, 1987).

Este ciudadano-mercado ya no se preocupa por forjar un país, un mundo ${ }^{6}$; se desinteresa de la política. Este desinterés se corresponde con la idea de individuo liberal, y con ellose trata de procurar la satisfacción de mis intereses, lo que implica que el interés común se reduce a satisfacer lo de cada uno. La formación ciudadana, y con ello el concepto de espacio público, adquiere por contenido la pululación de agentes de intercambio comercial, y dejar el forjamiento del mundo en manos de expertos. De este modo, la relación entre ciudadanos es una relación "interesada", esto es, una relación que comienza a partir de premisas tales como gasto, ganancia, inversión, etc. Desde mi punto de vista, por ejemplo, la crisis ambiental se debe a este tipo de formación; por ello es perentoria la politización de la educación.Educar en sentido político, pero no bajo el prisma de lo que por política se entiende hoy. ¿Por

6 Por mundo entenderé la concepción que Hannah Arendt sostiene a través de su obra. Tal concepto, de arraigo griego, implica lo que los ciudadanos, a través de la política, forjan. El mundo se forja mediante las relaciones entre ciudadanos y no meramente entre ser humano y naturaleza. Tales relaciones implican la comunicación, el diálogo, el uso del lenguaje en la forma de la opinión, puesto que cada ciudadano, al ser único, solo él puede decir algo acerca del mundo, de lo que ha sido forjado entre muchos, y los otros tienen, eventualmente, el requerimiento de aquella opinión, puesto que también les pertenece ese mundo, que solo los otros lo pueden decir. 
qué habría de politizarse la educación?, porque significa dotarla de aquellas cualidades para el ejercicio de lo público y de las decisionescomunes ${ }^{7}$. Pero bien cabe aquí preguntarse por esta pertinencia. El surgimiento de los Estados-nacionales está anclado en la despolitización, entendida como biopolítica o biopoder (Foucault, 2002), o como la hegemonía del animal laborans (Arendt, 1998), o como "economía doméstica" (Weber, 2004). La despolitización es indispensable para el desenvolvimiento de las políticas de las democracias liberales; pero de nuevo preguntamos: ¿por qué es importante la politización en la era de las democracias liberales? Porque la despolitización, por un lado, convierte la diferencia entre ricos y pobres, las diferencias sociales, en un asunto individual, en un problema del mercado, y bien sabemos que el mercado opera bajo el grito de guerra de "la mano invisible"; en cambio, al politizar la diferencia entre ricos y pobres aparecen los mecanismos por medio de los cuales se gesta esta diferencia (Rancière, 1997); aparece el mundo que los ricos han diseñado. Las democracias liberales deben borrar de raíz su origen, y el modo de hacerlo ha sido el ejercicio constante y permanente de persuadir a la población de que las actuales relaciones político-jurídico-sociales son naturales. El propio liberalismo lo atestigua así: el derecho natural, que con él se forja para darle legitimidad y legalidad, parte de la base de que somos "por naturaleza" libres, racionales, iguales y propietarios de nuestro cuerpo y de lo que este se apropie (Locke, 2011; Hobbes, 2010), respetando, claro está, las normas que regulan los modos de apropiación.

Pero, por otro lado, se trata de recuperar el concepto y práctica de espacio público "politizado", y para ello hay que retrotraerse a la Atenas de Pericles y a la Grecia clásica en general. La bibliografía es amplia y rigurosa con respecto a este tema, y los propios estudios acerca del espacio público ateniense nos brindan diversos ejes temáticos y de contenidos. Nosotros rescataremos algunos aspectos que nos puedan orientar en la implementación de una educación pública "política"9 en los países latinoamericanos.

$7 \quad$ Este concepto está relacionado con el de mundo, puesto que lo común a los ciudadanos atenienses es él. Queda excluida la posibilidad de entender lo común como la tenencia de suelo o tierra. Arendt, Hannah: La condición humana.

8 A raíz del concepto-directriz homo oeconomicus las relaciones entre los individuos miembros de la sociedad moderna son económicas. Esta suerte de "ontologización económica" de la realidad supone que la racionalidad de los ciudadanos no puede intervenir en el funcionamiento del mercado, puesto que este opera de modo natural, esto es, por fuera de toda racionalidad.

9 En el caso griego, como se verá, es redundante decir público político, puesto que lo público es político. 
Como bien se sabe, el espacio público ateniense estaba compuesto de ciudadanos, equivalentes a un porcentaje bien inferior al $20 \%$ de habitantes de la polis. El colchón en el que descansaba el espacio público ateniense era en el ámbito de la esfera privada (Arendt, 1998; Sennett, 2001 y 2011; Aristóteles 1873; Habermas, 1994; Finley 1990; Rancière, 1997). Estos ciudadanos eran iguales entre sí, no se debían obediencia entre ellos, esto es, no había relaciones de mando y obediencia, salvo las emanadas de la asamblea general, instancia máxima que convocaba a todos los ciudadanos a decidir acerca de los destinos de la polis. La igualdad suponía el ejercicio de la distinción y no de la mera diferencia. Diferentes somos los unos a los otros de modo natural; distintos somos los unos a los otros de modo político, es decir, artificial, emanado del actuar y el decir. La "identidad" del ciudadano se la otorgaban los otros en virtud de su actuar y de su hablar. El lenguaje jugaba un papel fundamental, puesto que ahí radicaba la posibilidad de lo común del mundo: la doxa era de primera importancia. La libertad era el horizonte de sentido del ciudadano griego, puesto que era lo que lo separaba de la zoe. Esta separación era, a su vez, de la esfera privada, lugar que compete a la satisfacción de las necesidades vitales de existencia, esto es, de la dimensión animal-natural que nos condiciona. Para el ciudadano ateniense la condición de "humano" era tomar distancia delámbito animal-natural que nos condiciona, pero en el interior mismo de esa condición, de tal modo que la separación ocurría por medio de la libertad de intervenir el continuo de la naturaleza que va, siempre, del nacer al morir.

En la naturaleza "no ocurre nada": la libertad hace posible gestar, comenzar, forjar, hacer emerger, surgir un nиеvo mundo en el interior mismo de la naturaleza. En este sentido, solo la política, y no la satisfacción de las necesidades y, por extensión, la acumulación de riqueza, proporciona el rango de "humano" al ser humano; de lo contrario estamos más cerca de la simple y pura animalidad.

A partir de este escueto relato acerca del espacio público ateniense habremos de pensar el concepto de público en el enunciado "educación pública".Sería, pues, una educación política; esto quiere decir: preparar a niños y niñas para gestar un nuevo mundo, un mundo que no se condiciona al ejercicio de la economía, más bien, se supedita, subordina, al ámbito de la política. Se trata, entonces, de generar estudiantes libres, pero no en el sentido actual del término, preñado de economicidad, sino de la libertad de serlo con otros y no por sustracción de los otros; libres en común, es decir, forjarse como tales en la medida de responder por sus actos y, a su vez, tener como horizonte a la especie humana y no la satisfacción constante y permanente de los intereses individuales, tal y como lo hacen (algunos) los animales. Implica lo anterior 
dotar a los estudiantes de las herramientas e instrumentos para la discusión, la reflexión, el diálogo, el discernimiento, la confrontación con los otros, reparando, claro está, que los otros son sus iguales. Habrá que anticiparse a una posible objeción: el derecho contemporáneo da por hecho que somos todos iguales, lo que es cierto; sin embargo, está igualdad jurídica anula las diferencias reales, esto es, las que emanan de las propias relaciones socio-económicas a partir de la idea liberal de igualdad natural ( $¡$ antes de nacer!). Habrá que concebir, ante todo, la disposición intelectual a discutir si es racional sostener que existe la "naturaleza humana”.

\section{REFERENCIAS}

Althusser, L. (1988). Ideología y aparatos ideológicos del Estado: Freud y Lacan.Buenos Aires, Argentina:Nueva Visión.

Arendt, H. (1998). La condición humana. Traducción de Ramón Gil Novales. Barcelona, España: Paidós Ibérica.

Arendt, H.(1997). ¿Qué es la política?Traducción de Rosa Sala Carbó. Barcelona, España: Paidós Ibérica.

Arendt, H. (2007).Responsabilidad y juicio. Traducción de Miguel Candel. Barcelona, España: Paidós Ibérica.

Arendt, H. (1987). Los orígenes del totalitarismo. Tres volúmenes. Madrid, España: Alianza Editorial.

Arendt, H. (1984).La vida del espíritu. El pensar, la voluntad y el juicio en la filosofía y en la política. Traducción de Ricardo Montoro Romero y Fernando Vallespin Oña. Madrid, España: Centro de Estudios Constitucionales.

Aristóteles. (1873). Política.Según edición de Patricio de Azcárate, Madrid.

Bowen, J. (1992). Historia de la educación occidental. Tres volúmenes. Barcelona, España: Herder.

Brossat, A. (2008). La democracia inmunitaria. Traducción de María Emilia Tijoux. Santiago de Chile: Palinodia.

Esposito, R. (2003). Communitas: origen y destino de la comunidad. Traducción de Carlo Rodolfo Molina Di Marotto. Buenos Aires: Amorrortu.

Esposito, R.(2005). Inmunitas: protección y negación de la vida. Traducción de Luciano Padilla López Buenos Aires: Amorrortu. 
Finley, M. I. (1990). El nacimiento de la política. Grijalbo.

Foucault, M. (2002). Defender la sociedad. Traducción de Horacio Pons.México: F. C. E.

Foucault, M. (2008). Nacimiento de la biopolítica. Traducción de Horacio Pons. Argentina: F. C. E.

Habermas, J. (1994). Historia y crítica de la opinión pública. México: Gustavo Gili.

Hayek, F. von. (1975). Los fundamentos de la libertad. Traducción de José Vicente Torrente. Madrid, España: Unión Editorial.

Hobbes, T. (2010). Leviatán o la materia, la forma y poder de una República eclesiástica y civil. México: F.C.E.

Horkheimer, M. (1973). Crítica de la razón instrumental. Buenos Aires: Editorial Sur.

Jaeger, W.(1957). Paideia: Los ideales de la cultura griega. Traducción de Joaquín Xirau y Wenceslao Roces. México: F.C.E.

Locke, J.(2011). Segundo ensayo sobre el gobierno civil. México: Porrúa.

Luc-Nancy, J. (2012). "Conloquium" en Communitas: origen y destino de la comunidad. Buenos Aires: Amorrortur.

Mészàros, I. (2008). La educación más allá del capital. Buenos Aires: Siglo Veintiuno.

Mises, L. von. (1996). Sobre liberalismo y capitalismo. Dos tomos. Barcelona, España: UniónEditorial.

Pineau, P., Dussel, I., Caruso, M. (2001) La escuela como máquina de educar.Buenos Aires: Paidós Ibérica.

Rancière, J. (1997). En los bordes de lo político. Traducción de Alejandro Madrid Zen. Santiago de Chile: Editorial Universitaria.

Sennett, R. (2001). Carne y piedra. El cuerpo y la ciudad en la civilización occidental. Madrid, España: Alianza.

Sennett, R. (2011). El declive del hombre público. Barcelona, España: Anagrama.

Weber, M. (2004). Economía y sociedad. Traducción de José Medina Echavarría, Juan Roura Parella, Eugenio Ímaz, Eduardo García Máynez y José Ferrater Mora. Ciudad de México: F. C. E. 